\title{
ENGINEERING IDENTITY: ANALYSING E-PORTFOLIOS IN A PROFESSIONAL COMMUNICATIONS COURSE
}

\author{
G. R. Nudelman \\ Professional Communication Studies Department \\ University of Cape Town \\ Cape Town, South Africa \\ e-mail: gabi.r.nudelman@gmail.com
}

\section{ABSTRACT}

Current research points to an increase in the inclusion of Information and Communication Technology (ICT) in higher education contexts. This study considers the e-portfolios created by a cohort of final-year electrical engineering students at a South African university. With an understanding of the homepage text as discourse, the study seeks to investigate how students identify as professional engineers. Qualitative analysis of the homepage text of the students' sites indicate that the students see themselves as technological innovators, all-rounders and leaders who are driven by passion to reach their goals and positively impact the world. The conclusions that can be drawn are that the students' identities as engineers are purposeful, multifaceted and evolving in relation to the changing nature of industry, and that they reflect the students' employability.

Keywords: e-portfolios, professional communications studies, engineering education, electrical engineering, Information and Communication Technology, higher education

\section{INTRODUCTION}

This research focuses on the use of e-porfolios within a professional communication skills course offered to electrical engineering students at a South African university. The study aims to determine how the e-portfolio homepages of these students reflect their developing identities as professional engineers. It thus contributes to the growing body of knowledge around how students in higher education are prepared for the workplace.

The professional communication skills course mentioned above is a compulsory course for all fourth-year students in the electrical engineering department at a South African university. It builds on more basic written and oral skills developed in a third-year professional communications course in order to prepare students for the challenges that they will face once they graduate from university and enter the engineering workplace. Using small group work, discussion and role-play, the course focuses on practical skills such as team work, negotiation skills, job interviews and pitching for potential funding. Students are assessed via the production of a number of outputs including a summary of a business plan, a poster for potential 
investors, a group presentation to potential investors, and a professional e-portfolio. Each of these outputs is assessed individually, besides for the poster which receives a group mark.

The e-portfolio task is a relatively new innovation in the course. Over the past few years, more emphasis has been put on online technologies in order to prepare the students for the digital world of work. This has primarily consisted of a focus on the development of a professional 'digital footprint' via social media such as Twitter, Facebook and LinkedIn. However, in 2015, following departmental training from a university Information and Communication Technology (ICT) specialist, the decision was taken to make the creation of an online e-portfolio a compulsory task to be evaluated for marks. This was in line with other course material that focussed specifically on preparing students to enter the workplace, including curricula vitae, cover letters for job applications and job interview skills.

During lecture time, students were shown some examples of other student e-portfolio sites. These were used to facilitate a discussion about the importance of creating professional online spaces and being proactive with regards to managing one's online reputation. The e-portfolio task was then set. Students were informed that they could use any online platform (for example Wix, Wordpress or Pathbrite) to create their e-portfolio site. The task was scaffolded, with two submission dates set. For the first, early in the semester, students were required to design their homepages, which had to include a brief overview and a link to a CV. This first submission was not graded, but lecturers did provide written feedback. The second submission, towards the end of the semester, was the completed e-portfolio site. This had to include information about a particular engineering project they had been working on for another fourth-year engineering course, however students were also encouraged to populate their sites with other relevant artefacts, for example supplementary images or videos, and content relating to other projects, research, awards or work experience. Students were assessed on the e-portfolio via a mark, with the task worth 100 marks out of a total of 600 for the course. Each student also received extensive written feedback on his/her e-portfolio.

The e-portfolio task has been designed as a way to help students consider issues central to the professional communications course. In particular, it provides a vehicle for students to synthesise their thinking about the professional image that they wish to portray as they enter the world of work with the opportunities for connection offered by online spaces. This requires them to consider issues such as strategic collection of content, appropriate design choices and user-friendliness of the site. The task also pushes the students, who are approaching the end of their undergraduate study, to begin considering their developing professional identities as engineers. This is an important bridging step between higher education and the workplace. With 
a particular focus on discourse, this article looks specifically at how students portrayed these identities on their e-portfolio homepages.

\section{LITERATURE REVIEW}

Internet-based learning activities such as the development of e-portfolios by fourth-year engineering students described above, is in line with the growth of the use of ICTs for learning and teaching in higher education. While acknowledging that a definitive e-portfolio definition does not exist, Strohmeier (2010, 268) understands e-portfolios as reflected and structured collections of electronic items, produced and used by a creator with the help of information systems in order to reach specific objectives. This very general explanation covers a range of different potential creators (individuals, groups and/or organisations) and objectives (for example, e-portfolios developed to showcase achievements or to serve as a repository for related documents). The electronic items included in an e-portfolio can include artefacts such as certificates, academic transcripts, curriculum vitaes, learning-diaries, blogs, wikis, presentations and photographs amongst others (Ward and Moser 2008, 14; Strohmeier 2010, 269). These artefacts are collected and presented in a systematic way in order to fulfil the objectives of the e-portfolio.

In a higher education context, Alexiou and Paraskeva (2010, 3049-3050) describe four common types of conventional portfolio usage:

- Assessment portfolio: students provide evidence of their competence in particular academic subjects areas and are assessed thereon.

- Showcase portfolio: students present projects that they have worked on in various subject areas.

- Development portfolio: students track and plan their personal development over time.

- Reflective portfolio: students reflect on their accomplishments and how these relate to particular learning goals.

Jaffer, Ng'ambi and Czerniewicz $(2007,131)$ highlight that while educational technology such as e-portfolios does have the potential to impact learning in higher education, contextualised teaching and learning needs should drive any ICT intervention, rather then the technology itself. Although e-portfolios can aid educators in assessing student performance, facilitating student reflection and displaying student achievement in a given subject area (Wuetherick and Dickinson 2015, 40), the technology needs to be embedded into pedagogical frameworks that 
promote learner-centred principles (Alexiou and Paraskeva 2010, 3048). One of the affordances provided by e-portfolios in this regard is their ability to be customised and configured by the students who make choices around artefacts, text and design. This personalisation of learning can result in a sense of ownership of the finished product (Alexiou and Paraskeva 2010, 3050) which can facilitate a 'deep’ approach to learning (Ramsden 2003, 47). In this way, students move beyond a get-the-task-done, 'surface' approach to tasks in order to relate previous knowledge to new knowledge and theoretical ideas to everyday knowledge.

In addition, development of e-portfolios can provide students with an opportunity to engage in an authentic learning experience (Reese and Levy 2009,3). This form of learning typically focuses on real-world, complex problems and their solutions, with students carrying out tasks that match the real-world tasks of professionals in practice (Lombardi 2007, 2-3). In developing e-portfolios, students move beyond disconnected practice exercises or preparation for what their sites would hypothetically look like. Rather, each student creates a real, active online space, engaging in the processes of deciding which artefacts to include, how to organise their content and what design choices will best contribute to the achievement of their eportfolios' objectives. This level of student control is essential for the effective implementation of ICT into higher education as it provides space for students to determine their own routes through academic material and thereby to engage with what they are learning at a high cognitive level (Ramsden 2003, 98, 152).

There are many examples of e-portfolios being used in engineering education for different purposes. At the University of Notre Dame in the United States (US), for example, e-portfolios have been integrated into the first-year 'Introduction to Engineering' course as a way to guide students' reflection on their education, specifically their engineering major choice, the progress of their projects and their exploration into professional engineering practice (Aguiar, Ambrose, Chawla, Goodrich and Brockman 2014). At the University of Washington, also in the US, undergraduate engineering students attend a 'portfolio studio' where they are guided through the process of constructing a preparedness e-portfolio, which demonstrates their preparedness for a future activity such as industry work or entry into postgraduate programmes (Sattler and Turns 2015). Finally, Terkowsky, Haertel, Bielski and May (2014) from TU Dortmund University in Germany illustrate various ways in which mobile technology can be used in conjunction with an online e-portfolio system with the aim of facilitating and fostering creative laboratory learning for engineering students.

The e-portfolio task that forms the focus of this study has been framed as a way for the fourth-year electrical engineering students to take ownership of their 'digital footprints' as they 
prepare to enter the world of work. In this regard, Strohmeier $(2010,271)$ compares e-portfolios to other more traditional ways to apply for jobs, for example, hard-copy document folders, email attachments and web-based forms. He shows that e-portfolios consist of a broader set of items, which can include multimedia such as videos, images and sound, and that this means they surpass the other methods in scope, depth and documentation of multiple facets of a potential job applicant. However, a survey of employers by Ward and Moser (2008) suggests that the use of e-portfolios by human resource managers is generally low across all industries. The reasons given for this include not being familiar with the technology, time constraints, cost, and not seeing the value of e-portfolios (Ward and Moser 2008, 13). The authors conclude that universities adopting e-portfolios as tools for career development should take responsibility for educating employers as to their value.

\section{THEORETICAL ORIENTATION}

This study takes as a theoretical base a move away from the conceptualisation of the development of workplace-readiness skills, such as those taught in the professional communication skills course described above, as isolated skills that are picked up by the student during higher education and transferred neatly and wholly into the workplace once he/she is employed. This understanding, which Beach $(1999,106)$ terms 'the transfer metaphor', relies on an unproblematic, unidirectional transporting of skills from one context to another. It assumes that places and spaces, such as higher education institutions and workplace contexts, remain static and stable while the individual moves between them, thus ignoring the 'continuous dynamics through which space is open, relational and multiple, socially produced and productive of social relations' (Fenwick 2013, 361).

In moving beyond the transfer metaphor, Beach suggests an alternate way of understanding how skills taught in higher education can prepare students for the challenges they may face as professionals. He conceives of this as a bid to understand how knowledge generalises across social contexts, framing continuity and transformation of knowledge as multiple, interrelated processes rather than a single decontextualised application of skill (Beach 2003, 41). This manifests in a move away from simply observing how graduates apply a particular skill (for example, in the case of this study, the development of an e-portfolio), to a focus on trying to understand 'the construction of new knowledge identities, ways of knowing, and new positionings of oneself in the world' (Beach 2003, 42).

Utilising Gee’s notion of discourse as 'language-in-use' $(2014,19)$ can provide a lens onto how these new knowledge identities are constructed and embodied. According to his definition, 
discourse is about the relationship between language and context and the way people use language to signify membership of particular identities that are enacted and recognised by different social and cultural groups and formations in society $(2014,23)$. Allie et al. understand this as 'certain ways of using language, acting, interacting, behaving, believing, using tools, sign systems, and so forth, which characterise a particular community’ (2009, 361). Gee does acknowledge the fluidity, multiplicity and contested nature of these identities, but core to his argument is the notion of identity as performance; to embody identities people have to 'talk the right talk, walk the right walk, behave as if they believe and value the right things, and wear the right things at the right time and right place' (Gee 2014, 24).

Understanding identity as performance means that texts that are produced can be read as discourse. This is because they are 'situated texts' (Dunsmore, Turns, and Yellin 2011, 332), which means that they are inextricably linked to the social context in which they have been created. They thus reflect the identities of those who have produced the discourse, making it possible for the reader to use them as a way to begin to understand more about those who have created the texts. In the case of this study, this means a focus on how the fourth year engineering students have taken on the discursive identity of engineers (Brown, Reveles, and Kelly 2005, 783) as evidenced by the text on their e-portfolio homepages. This can provide researchers with a way to analyse whether and how students have adopted new knowledge identities of professional engineers during their studies.

Eliot and Turns (2011) highlight that understanding how engineering students develop professional identities is important for two reasons. Firstly, helping students become engineers is a core outcome of engineering higher education, both in terms of technical knowledge and in terms of workplace readiness. Secondly, how students identify professionally could be a mediator for other important educational issues. For example, graduates who leave higher education strongly identifying as engineers may be more likely to remain in industry once they enter the workplace, an outcome that would be most desirable in a country such as South Africa which experiences a severe shortage of engineers (Du Toit and Roodt 2009). Thus, using student work to understand how students adopt the discursive identities of engineers (as opposed to simply applying an isolated set of workplace skills) and actually become engineers can have valuable repercussions for engineering education in South Africa.

\section{RESEARCH QUESTION}

How does the text on students' e-portfolio homepages reflect their identities as professional engineers? 


\section{RESEARCH METHODOLOGY}

For the purposes of this study, a qualitative approach towards the research was taken in order to provide for an open-ended, inductive exploration (Terre Blanche, Kelly, and Durrheim 2006) of the way students portray their identities on their e-portfolio homepages. Quantitative research does provide the researcher with the tools to develop findings that are generalisable and comparable between different contexts (Durrheim and Painter 2006). However, this study, which seeks to explore how students perform their identities through language use in a specific context (in this case, the homepage of the students' e-portfolio), is better suited to a research paradigm that harnesses and extends 'the power of ordinary language and expression to help us understand the social world we live in' (Terre Blanche, Kelly, and Durrheim 2006, 274).

The data for the study was gathered through an analysis of the text on e-portfolio homepages of the 148 fourth-year engineering students enrolled in the professional communication skills course. Where students included an 'About me' section on their websites, these were also included in the study since they specifically deal with how the students portray their identities. Of the students, 18 were female and 130 were male. The homepage text was coded using the Computer Assisted Qualitative Data Analysis Software package, Nvivo. Three category levels were used for the analysis: organisational, theoretical and substantive (Maxwell 2012). Organisational categories refer to broad issues that are established prior to data collection. In this study, these referred to issues such as skills, attributes, goals, and motivations. Theoretical categories refer to those that relate to prior theory, which in this study referred to how students portrayed their discursive identity as engineers. Finally, substantive categories are descriptive, including the description of participants' concepts and beliefs. In this study, these categories included things like childhood engagement with engineering, personal characteristic and passions.

\section{FINDINGS}

\section{Technological innovators}

Many of the students referred to themselves as innovators on their homepages. Innovation was seen as something that could inspire others, as something that one can be committed to and as a realm in which new and exciting ideas for the future can be formed. One student explained: 'I aspire to apply the knowledge of science and engineering to innovate technology that will improve the overall quality of life'. Engineering was described as a tool through which 
innovation can be achieved because it stimulates creativity, particularly with regards to putting technology to work for the benefit of humankind. Students mentioned particular examples of this, including high voltage transformers, smart devices, embedded systems and general purpose graphics processing units. For a number of students, this enthusiasm regarding technology was one which had been present from a young age. As one described:

Ever since I was a child, I have always had a fascination with electronic technology. I loved (and still do) the way in which, with a simple tap, click or push, sounds and images could result. I enjoy the way in which new technologies can help people and change lives.

Many students also shared their particular technological skills on their homepages. For example, a number listed the programming languages in which they were proficient, such as Python and $\mathrm{C}++$. Others highlighted skills in design and system optimisation. What was evident for those students who emphasised innovation on their homepages, however, was a clear sense of engineering enabling them to play a part in shaping the future through the utilisation of technology.

\section{Driven by passion}

A number of students referred to 'passion' on their homepages. Some referred to a passion for engineering in general, with a number sharing stories about how, as children, they would tinker with electronics and electrical appliances. One described how, in primary school, her pencil case was packed with LED lights and little motors instead of stationary and that this passion resulted in her choosing engineering as a career choice. Another student explained: 'When I decided to do electrical engineering it was from a passion which rose from the thirst of knowing how things work'.

Other students were more specific about the focus of their particular passion. Two themes emerged here. The first was a passion for specific fields of engineering. Some of these included embedded systems, advanced robotics, digital electronics, control engineering and power engineering. The second was a passion for social issues, with a particular emphasis from a number of students on the empowerment and education of young people. While this did not link directly to their engineering studies, this desire to positively impact people's lives is discussed further in the next section.

\section{World changers}

On their homepages, many of the engineering students articulated the idea that the skills and 
knowledge developed over the course of their engineering studies would be used as a way to make a positive difference in the world. Students stated that the technological knowledge that they have developed and will go on to master could be put to work enriching lives and helping humankind in healthy and sustainable ways. A number of students referred specifically to electricity, and the role that they want to play in developing sustainable energy and renewable resource solutions. There was also reference to the role that they, as engineers, would play in bringing the potential of the digital realm to ordinary people. One student explained that this 'opens the door for applications where people can benefit directly from this interaction such as disaster management and rescue, and mobility assistance for disabled persons’.

In addition to harnessing specifically engineering-related knowledge in a bid to improve the world, many students also referred to social causes that they feel strongly about. As mentioned earlier, many of these had a specifically youth-related focus, including educating school children in rural areas, leading study groups, running career guidance in schools and tutoring, mentoring and other such work through the university's student-led outreach organisation. Some students also volunteer with organisations in the areas of violence against women, poverty alleviation and environmental sustainability, and mentioned these causes on their e-portfolio homepages.

\section{Problem solvers}

One of the students referred to engineering as 'the art of problem solving' on his/her homepage. This echoed a common theme in students' text: that of solving society's problems. Students fundamentally link this to the essence of engineering. They describe these problems in different ways, including 'complex problems’; 'problems faced by society in everyday life’; 'real-world problems'; and 'problems people don't know they have'. However these are defined though, students credited their aptitude for problem solving to what they have been taught as engineersin-training. As one student writes:

In an engineering degree you are forced to learn quickly and most importantly apply your new knowledge to real world problems. This has prepared me to easily adapt and contribute to any environment that I am put in.

When describing how they approach problems, a number of students use words like 'rational', 'systematic', 'analytical' and 'logical'. A number also make specific mention of mathematics and physics and the ways that these fields have taught them to think. 


\section{Leaders}

A common theme running through the students' homepage text was reference to themselves as leaders. Students provided evidence for this by sharing how they had developed their leadership skills. For some, these had arisen from their participation in sporting codes. Others cited their leadership positions in student organisations including the Ghana Society and the Y Society, the latter a religious grouping on campus. Finally, some students credited their leadership skills to heading up academic projects, although this was referred to quite generally by students and specific examples were not provided.

While most students used the word 'leadership' without defining the specific meaning thereof, some engaged more deeply on their homepages with exactly how they embody these skills. For example, one student wrote: 'I am a person who is keen on understanding people and knowing what makes them who they are. This helps me become a better leader since I know the type of motivation different people respond to.' Others encapsulated leadership as listening to peers and considering their opinions, taking responsibility for actions, and providing people with a platform through which to showcase their potential.

\section{All-rounders}

Most of the students used their e-portfolio homepages to show that they are well-rounded individuals. One of the ways in which they did this was by sharing the extracurricular pastimes with which they engage. The most commonly cited activity was sports, with students mentioning their involvement in soccer, rugby, surfing, mountain climbing and generally exercising and keeping fit. Another commonly cited pastime was music, with many students sharing that they play instruments, are members of bands and/or enjoy writing music. Other activities mentioned by multiple students included photography and engagement with literature, electronics and current affairs. While most students simply listed their pastimes, others explained how these relate to their choice of study. For example, one student wrote:

My interests and hobbies have played a big role in my career choice, since I realised in high school that I cannot be successful in a profession that I do not enjoy. For this reason, it is no surprise that I am very fond of computers. Playing video games and programming are two of the main activities I enjoy doing.

Another way that students showed their all-roundedness was by highlighting the 'generic' skills and attributes that they possess. In terms of skills, many students mentioned teamwork, communication (both written and oral) and ability to work with people from diverse backgrounds as areas in which they particularly excelled. In terms of personal attributes, there 
were certain qualities that many students reported possessing. Those that were mentioned most often included being hard-working, relishing challenges, learning quickly and being friendly, out-going and humourful. Several students also made particular mention of creativity, with this manifesting through involvement with music, art and design.

\section{Goal-driven}

Many students also used their homepages to outline their goals for the future. For a handful of students, these were short-term goals focussed on their studies. For example, one student wrote: 'My goal is to graduate with a first class honours degree in Mechatronics'. The majority of students, however, were more focussed on describing their long-term goals. For many, this involved Masters studies in electrical engineering-related fields such as radar, renewable energy, robotics, biomedical engineering and power electronics. Other students described the sorts of industries that they would like to work in in quite general terms. These included telecoms, alternative energy, aeronautics, the military, power systems engineering and virtual reality. There were a number of students, however, who were quite specific about their goals. For example, one student stated:

In the next ten years, I plan to work for a company where I will be working on digital electronic circuit design and development. After this period, when I have gained extensive experience in this field, I plan to open a consulting company.

Some students described their future goals in terms values as opposed to plans. These goals encompassed the kinds of principles that the students hoped would underpin their futures. For example, one student wrote: 'I dream about achieving something great without having to abandon my morals and be remembered for this' and another stated that he 'strives to achieve his goal of living a life inspired by love and guided by knowledge'.

\section{CONCLUSIONS}

The findings show that the students largely perceive their relationship with engineering as extending beyond a simple job choice. Rather, for many, it is a vocation, serving as the point of intersection of their short-term and long-term goals, their hopes for the future of mankind, personal skills and attributes, and innovative ideas. This is evident in the way many explain that they exhibited a tendency towards electrical engineering when they were children. In addition, the fact that so many used the term 'passion' to describe how they feel about electrical engineering in general and the specific fields in which they are interested, shows that they relate 
to the profession beyond the enactment of particular tasks simply in order to earn a living. This furthermore is reflected in the goals that the students wrote about, which were not expressed in terms of corporate development or financial gain, but rather in terms of using engineering to elicit positive change in the world. In fact, the concept of engineering having the potential to make a difference in the future was clearly evident throughout the homepages. Thus students perceive their identities as engineers as one of purpose, and in doing so, locate themselves as having the potential to effect real change in the world.

The findings also show that the students see themselves as embodying the qualities of what Conlon (2008) terms the 'New Engineer'. Extending engineering beyond the enactment of decontextualised technical tasks, this conception views contemporary engineers as broad based professionals who are socially and environmentally responsible (Conlon 2008, 151). The students' homepage text shows that their identities as engineers reflect this multidimensional conception of the profession in many ways. Firstly, many students mentioned their desire to engage further in fields of environmental concern such as renewable and sustainable energy and showed an awareness of and desire to intervene in wide-ranging social issues. Secondly, being able to collaborate with individuals from diverse backgrounds was mentioned by many students as a positive quality that they possessed. Finally, students cited a wide variety of personal qualities, such as communication skills, teamwork, people skills and friendliness that they feel they embody. These show their readiness to engage with others within and outside of the engineering industry. It is clear, therefore, that students conceive of their engineering identities as multifaceted, evolving, and responsive to the current contemporary context. It is interesting to note, however, that only five students made any mention of entrepreneurship and the goal of one day starting their own business. This indicates that most envision joining formal industry when they begin their lives as professionals.

Finally, the students have clearly made an effort to represent their professional identities positively on their homepages. This is evident through the favourable attributes that they cite such as determination, commitment and dependability; the positive tone they adopt throughout (for example by framing their career choice as a passion); and the enthusiasm that they present for the field of electrical engineering. In these ways they use their homepages to present themselves as appealing to industry. These students clearly take ownership of their own employability and shape their professional identities in such a way that reflects the requirements of a potential employer. This is in line with the literature which states that contemporary students are expected to constantly maintain their own employability (Tomlinson 2012, 413) in order to succeed in the labour market. According to this perspective, responsibility is placed on 
the individual student to make him/herself employable. Then, if he/she does not get employed, it is understood as a failing in his/her skillset, as opposed to the vagaries of the economy or the labour market. The students' homepages show that the students are aware of the kinds of skills, attributes and characteristics that employers look for, and have shaped their professional identities to reflect these.

Thus, reading the students' e-portfolios as situated texts provides an opportunity to understand how this cohort of fourth year electrical engineering students reflect and represent their discursive identities as engineers. The study is located within the context of a professional communications course aiming to prepare students for the working world and the themes that emerge indicate that the students actively portray themselves as employable to potential employers. However, beyond a narrow concern for entering the workplace, the students show that an integral part of being an engineer involves being equipped to make positive changes in the world. In addition, they show that their professional identities are multi-dimensional, dynamic and responsive to the modern context in which they are functioning. That so many students express their passion for engineering shows that they would be motivated to work in the industry in the future, which could have a positive affect on the engineering shortage in South Africa. Moreover, that the students' identities as engineers are located within the contemporary context shows that they are able to make connections between the practical and theoretical engineering education that they receive whilst at university and wider South African and global issues.

These findings also point to the potential usefulness of e-portfolios within a higher education context. Through the authentic learning experience of creating an online site, the students in this study were challenged to find ways to synthesise their experiences and achievements to date, their personal identities and their goals for the future. In doing so, they reflected on how they wished to portray themselves professionally. By providing the vehicle for this expression of identity, the e-portfolios offered a bridge between higher education and the professional world the students will soon be entering. While this study is focussed on engineering education, the implication is that the creation of e-portfolios could provide powerful learning opportunities across higher education disciplines, particularly with regards to facilitating workplace readiness.

\section{FURTHER RESEARCH}

There is much potential for future research arising out of this study. While this study has focussed on how the text on the students' homepages reflects their discursive identities as 
engineers, future studies could expand to take into account the multi-modal aspects of the eportfolios. For example, they could also analyse visual aspects such as photographs and other graphics, as well as aspects of design such as colour and font choices. In addition, future studies could incorporate an analysis of the artefacts that students choose to include on their e-portfolio sites in order to understand how these reflect their identities. Finally, while this study has used as its sample a full engineering class cohort, there is also scope for comparison between different groups of students. For example, future studies could examine whether and how the findings differ for female and male students or traditional and mature students.

\section{REFERENCES}

Aguiar, Everaldo, G. Alex Ambrose Ambrose, Nitesh V. Chawla, Victoria Goodrich and Jay Brockman. 2014. Engagement vs Performance: Using electronic portfolios to predict first semester engineering student persistence. Journal of Learning Analytics 1(3): 7-33.

Alexiou, Aikaterini and Fotini Paraskeva. 2010. Enhancing self-regulated learning skills through the implementation of an e-portfolio tool. Procedia-Social and Behavioral Sciences 2(2): 3048-3054.

Allie, Saalih, Mogamat Noor Armien, Nicolette Burgoyne, Jennifer M. Case, Brandon I. Collier-Reed, Tracy S. Craig, Andrew Deacon, et al. 2009. Learning as acquiring a discursive identity through participation in a community: Improving student learning in engineering education. European Journal of Engineering Education 34(4): 359-367.

Beach, King. 1999. Consequential transitions: A sociocultural expedition beyond transfer in education. Review of Research in Education 24(1): 101-139.

Beach, King. 2003. Consequential transitions: A developmental view of knowledge propogation through social organizations. In Between school and work: New perspectives on transfer and boundarycrossing, by Tuomi-Gröhn Terttu and Yrjö Engeström. 1st Edition. Advances in Learning and Instruction Series. Amsterdam; Boston: JAI Press.

Brown, Bryan A., John M. Reveles, and Gregory J. Kelly. 2005. Scientific literacy and discursive identity: A theoretical framework for understanding science learning. Science Education 89(5): 779-802.

Conlon, E. 2008. The new engineer: Between employability and social responsibility. European Journal of Engineering Education 33(2): 151-159.

Du Toit, Rènette and Joan Roodt. 2009. Engineers in a developing country: The profession and education of engineering professionals in South Africa. Cape Town, South Africa: HSRC Press.

Dunsmore, Katherine, Jennifer Turns and Jessica M. Yellin. 2011. Looking toward the real world: Student conceptions of engineering. Journal of Engineering Education 100(2): 329-348.

Durrheim, Kevin and Desmond Painter. 2006. Collecting quantitative data: Sampling and measuring. In Research in practice: Applied methods for the social sciences, 132-159. 2nd Edition. Cape Town: University of Cape Town Press.

Eliot, Matt and Jennifer Turns. 2011. Constructing professional portfolios: Sense-making and professional identity development for Engineering undergraduates. Journal of Engineering Education 100(4): 630-654.

Fenwick, Tara. 2013. Understanding transitions in professional practice and learning. Journal of Workplace Learning 25(6): 352-367.

Gee, James Paul. 2014. An introduction to discourse analysis: Theory and method. 4th Edition. Oxon, New York: Routledge.

Jaffer, Shaheeda, Dick Ng'ambi and Laura Czerniewicz. 2007. The role of ICTs in higher education in 
South Africa: One strategy for addressing teaching and learning challenges. International Journal of Education and Development Using ICT 3(4).

Lombardi, Marilyn M. 2007. Authentic learning for the 21st century: An overview. Educause Learning Initiative 1(2007): 1-12.

Maxwell, Joseph Alex. 2012. A realist approach for qualitative research. Thousand Oaks: SAGE Publications.

Ramsden, Paul. 2003. Learning to teach in higher education. 2nd Edition. London, New York: Routledge/Falmer.

Reese, Michael and Ron Levy. 2009. Assessing the future: E-portfolio trends, uses and options in higher education. Educause Centre for Applied Research.

Sattler, Brook and Jennifer Turns. 2015. Preparedness portfolios and portfolio studios: Supporting selfauthoring engineers. International Journal of ePortfolio 5(1): 1-13.

Strohmeier, Stefan. 2010. Electronic portfolios in recruiting? A conceptual analysis of usage. Journal of Electronic Commerce Research 11(4): 268-280.

Terkowsky, Claudius, Tobias Haertel, Emanuel Bielski and Dominik May. 2014. Bringing the inquiring mind back into the labs: A conceptual framework to foster the creative attitude in higher engineering education. In Global Engineering Education Conference (EDUCON), 2014 IEEE, 930-935. IEEE. http://ieeexplore.ieee.org/xpls/abs_all.jsp?arnumber=6826209

Terre Blanche, Martin, Kevin Kelly and Kevin Durrheim. 2006. Why qualitative research? In Research in practice: Applied methods for the social sciences, ed. Martin Terre Blanche, Kevin Durrheim and Desmond Painter, 271-284. 2nd Edition. Cape Town: University of Cape Town Press.

Tomlinson, Michael. 2012. Graduate employability: A review of conceptual and empirical themes. Higher Education Policy 25(4): 407-431.

Ward, Chris and Chris Moser. 2008. E-portfolios as a hiring tool: Do employers really care? Educause Quarterly 31(4): 13-14.

Wuetherick, Brad and John Dickinson. 2015. Why ePortfolios? Student perceptions of ePortfolio use in continuing education learning environments. International Journal of ePortfolio 5(1): 39-53. 